\title{
ADVANCED NEW LEAD AND DUST FREE FORMULA
}

GC Europe announces the introduction of GC Aroma Fine DF III, to replace the alginate impression material GC Aroma Fine Dust Free. GC Aroma Fine DF III, manufactured in Japan, has an advanced new lead and dust free formula of ultra-fine alginate particles with significantly enhanced powder-water affınity.

The improved affinity for water gives easier and quicker mixing without bubbles or inconsistencies, a smoother surface for accurate impressions and a better taste with no excessive salivation.

The mixture also has ideal thixotropic properties so it flows easily under light pressure without causing gagging. It features a fast 'snap-set' which gives sufficient working time but reduces time in the mouth and adhesion to hydrocolloid materials.

The properties of new GC Aroma Fine DF III make an alginate impression material that makes it quicker and easier to take accurate impressions with any type of patient.

Aroma Fine DF III will be delivered in two shrink wrapped boxes of $5 \times 1 \mathrm{~kg}$.

\section{Reader response number 57}

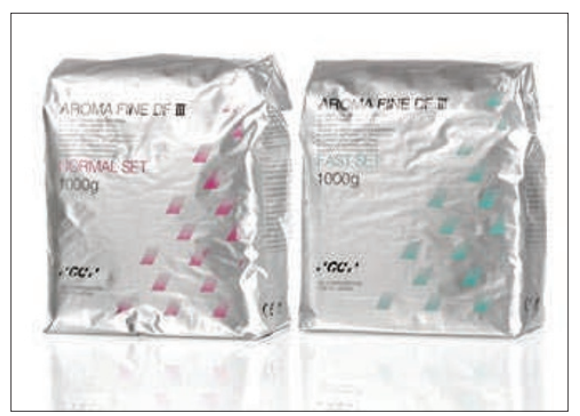

\section{PIONEERING NEW WEBSITE FOR VSS}

When a dental practice refers a patient to a specialist, supervision of that patient's welfare is temporarily handed over elsewhere. For some dentists, this is less than satisfactory and for them, Visiting Specialist Services (VSS) provides the solution.

VSS is an organisation of experienced clinicians and dental care professionals who go to the patient's practice so their care can be monitored by the referring dentist. The service to dental practices has just been extended to give referring dentists even greater control. VSS has a new website (www.visitingspecialistservices.co.uk) supported by a data-

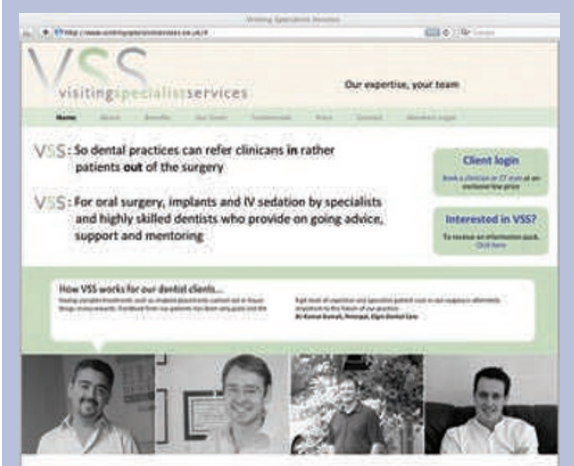

base, where clients can manage and monitor their patients' care, from booking them in for their treatment to checking records such as scans and X-rays.

The database is coded in such a way that it automatically triggers administrative responses. Several days before an appointment, the practice will be sent a reminder. For instance, if the patient is booked for sedation, the practice will get an email asking if an escort has been arranged and if the patient has been given pre- and post-operative guidance notes.

For the practice, it is a significant advantage to be able to involve the patient in the booking of the clinician and choice of date and time. It can all take place while the patient is still in the chair.

After the patient is booked in for a treatment, the clinician who has been chosen will be emailed so he or she can put the date in their diary and the practice gets an email confirmation that the session is booked. Currently, services are limited to the South East of England.

Reader response number 58 